\title{
Alcohol-Related Diagnoses and All-Cause Hospitalization Among HIV-Infected and Uninfected Patients: A Longitudinal Analysis of United States Veterans from 1997 to 2011
}

\author{
Christopher Rentsch ${ }^{1,2,3}$, Janet P. Tate ${ }^{2,3}$, Kathleen M. Akgün ${ }^{2,3}$, Stephen Crystal ${ }^{4}$, Karen \\ H. Wang ${ }^{2,3}$, S. Ryan Greysen ${ }^{5}$, Emily A. Wang ${ }^{3}$, Kendall J. Bryant ${ }^{6}$, David A. Fiellin ${ }^{3}$, Amy \\ C. Justice ${ }^{2,3}$, and David Rimland ${ }^{1,7}$ \\ ${ }^{1}$ Infectious Diseases, Atlanta VA Medical Center, Decatur, GA \\ ${ }^{2}$ Research, VA Connecticut Healthcare System, West Haven, CT \\ ${ }^{3}$ School of Medicine, Yale University, New Haven, CT \\ ${ }^{4}$ School of Social Work, Rutgers University, New Brunswick, NJ \\ ${ }^{5}$ Division of Hospital Medicine, University of California, San Francisco, CA \\ ${ }^{6}$ National Institute on Alcohol Abuse and Alcoholism, National Institutes of Health, Bethesda, MD \\ ${ }^{7}$ School of Medicine, Emory University, Atlanta, GA
}

\section{Abstract}

Individuals with HIV infection are living substantially longer on antiretroviral therapy, but hospitalization rates continue to be relatively high. We do not know how overall or diagnosisspecific hospitalization rates compare between HIV-infected and uninfected individuals or what conditions may drive hospitalization trends. Hospitalization rates among United States Veterans were calculated and stratified by HIV serostatus and principal diagnosis disease category. Because alcohol-related diagnoses (ARD) appeared to have a disproportional effect, we further stratified our calculations by ARD history. A multivariable Cox proportional hazards model was fitted to assess the relative risk of hospitalization controlling for demographic and other comorbidity variables. From 1997-2011, 46,428 HIV-infected and 93,997 uninfected patients were followed for 1,497,536 person-years. Overall hospitalization rates decreased among HIV-infected and uninfected patients. However, cardiovascular and renal insufficiency admissions increased for all groups while gastrointestinal and liver, endocrine, neurologic, and non-AIDS cancer admissions increased among those with an alcohol-related diagnosis. After multivariable adjustment, HIVinfected individuals with an ARD had the highest risk of hospitalization (hazard ratio 3.24, 95\% CI $3.00,3.49)$ compared to those free of HIV infection and without an ARD. Still, HIV alone also conferred increased risk (HR 2.08, 95\% CI 2.04, 2.13). While decreasing overall, risk of all-cause hospitalization remains higher among HIV-infected than uninfected individuals and is strongly influenced by the presence of an ARD.

Corresponding author and requests for reprints: Christopher Rentsch, VA Connecticut Healthcare System, 950 Campbell Avenue, West Haven, CT 06516, Christopher.Rentsch@ va.gov, Mobile: +1 770-580-0860, Fax: +1 203-937-4926. 


\section{Keywords}

inpatient care; HIV; substance abuse; clinical epidemiology; aging

\section{INTRODUCTION}

Since the availability of combination active antiretroviral therapy (ART), aging HIVinfected (HIV+) patients are increasingly hospitalized for non AIDS-defining conditions, such as cardiovascular, cerebrovascular, respiratory, and non-AIDS cancer complications (1-6). Although their risk for many of these conditions is increased due to their HIV infection $(3-5,7,8)$, few recent publications have compared hospitalizations among HIV+ individuals with demographically and behaviorally similar uninfected individuals. One 2006 study from Canada (9) compared hospitalizations among HIV-infected and uninfected individuals; none have been conducted in the United States.

Of special note, alcohol abuse, dependence, and other alcohol-related diagnoses (ARD) (e.g., alcoholic liver disease, alcoholic gastritis), are common among HIV+ patients $(10,11)$. HIV+ individuals may be particularly susceptible to harm from alcohol for several reasons. First, alcohol use decreases adherence to ART (12). Second, alcohol may contribute to microbial translocation and may exacerbate the state of chronic inflammation thought to be driving an increased risk of many age-associated, non-AIDS conditions among those with HIV infection (13). Third, even low levels of alcohol use are associated with hepatic fibrosis (14) and can aggravate the harmful effects of HIV infection (15) and of hepatitis C infection (16) on the liver. Fourth, continued alcohol use may exacerbate depression $(17,18)$ and other forms of mental illness. Finally, continued alcohol use may interfere with patient's efforts to stop smoking, control hypertension, or proactively manage their healthcare (17, 19-21).

ARDs are strongly associated with the risk of hospitalization among uninfected populations (22), and a recent systematic review showed a variable impact of ARDs on hospitalizations among HIV+ persons (23). Half of the reviewed studies suggested a significant increase in hospitalizations among HIV+ patients with an ARD compared to those without an ARD (23-26); and half reported no association (27-30). An important limitation to these studies was the lack of comparison to uninfected populations $(1-3,23)$. Using United States Veterans Administration Healthcare System (VA) data collected on all HIV+ patients in care and their uninfected counterparts, we compare hospitalizations by HIV status and ARD history, overall and by principal diagnosis from 1997 to 2011.

\section{METHODS}

\section{Study Cohort}

The Veterans Aging Cohort Study (VACS) has been well described $(31,32)$. In brief, VACS is an ongoing longitudinal study that includes HIV+ patients and an age/race/site-of-care matched control group of uninfected patients in care. This analysis included all HIV+ VACS patients who initiated care in the VA between October 1, 1996 and December 31, 2011 and 
their uninfected controls. Hospitalizations were counted after January 1, 1997 and hospitalization rates were calculated per calendar year. There were 254 controls who seroconverted during follow-up and were removed from these analyses.

The development of VACS has been approved by the Institutional Review Boards of the VA Connecticut Healthcare System and Yale University School of Medicine, granted a waiver of informed consent, and deemed HIPAA compliant.

\section{Hospitalizations and Alcohol-Related Diagnoses}

Hospitalization data were extracted from the national VA electronic medical records, Medicare, and Medicaid databases. However, due to the large number of duplicate hospitalization records between the Medicare and Medicaid databases among this patient population (many of these patients qualify for both Medicare based on disability or age, and Medicaid based on income), we did not include data from the Medicaid databases in these analyses. Using both unique patient identifiers and hospitalization dates, any further duplicate record of a single hospitalization was removed from the analysis. In all instances of duplicate hospitalizations, the VA records were kept. A hospitalization was defined as any admission that consisted of an overnight stay. For each hospitalization, an International Classification of Diseases, Ninth Revision (ICD-9) code was recorded denoting the principal diagnosis. We categorized these principal diagnoses to be in concert with previously published VACS studies $(6,11,33)$ and for those ICD-9 codes not previously explored in a VACS study, as suggested in other published studies examining hospitalization (see Table, Supplementary Material) (3). A list of the remaining ICD-9 codes were categorized and agreed upon by two experienced clinicians (DR and ACJ). ARDs were similarly defined by ICD-9 codes (see Table, Supplementary Material). Patients were considered to have an ARD if they had either two outpatient diagnoses or one inpatient diagnosis within the VA during the study period. This is the standard definition used in VACS.

\section{Variable Definitions}

Other data collected were the date of VACS enrollment, age at baseline, sex, race, and comorbidities, including hypertension, diabetes, chronic obstructive pulmonary disease (COPD), chronic hepatitis B, hepatitis $\mathrm{C}$, liver disease, anemia, non-AIDS cancers (bladder, breast, buccal cavity and pharynx, digestive system, endocrine system, eye and orbit, female genital system, Hodgkin's, ill-defined, kidney, leukemia, lung, melanomas, male genital system, multiple myeloma, non-epithelial skin, penile, prostate, skin, stomach, testicular, ureter, urinary system, urethra), cardiovascular disease (myocardial infarction, coronary artery disease, heart failure, transient ischemic attack, peripheral vascular disease, stroke, ischemic stroke), drug-related diagnoses, and psychiatric diagnoses (depression, anxiety, post-traumatic stress disorder, schizophrenia, schizoaffective disorder). All comorbidities were routinely collected within the VACS database using ICD-9 codes (see Table, Supplementary Material). The date of diagnosis for each comorbidity was defined as the second outpatient date if the patient was seen in an outpatient setting or the discharge date if the patient was seen in an inpatient setting. A comorbidity was considered present at cohort entry if the diagnosis date occurred before or within one year after VACS enrollment. 


\section{Statistical Analyses}

We compared demographic characteristics between HIV+ and uninfected patients using two-sided Wilcoxon Rank-Sum (z) and chi-square $\left(\chi^{2}\right)$ tests (34). Annual hospitalization rates were calculated over the study period. For each calendar year, the numerator was the number of unique patients active within the healthcare system and hospitalized at least once, and the denominator was the total number of unique patients active within the healthcare system. We considered a patient to be active within the healthcare system if they had any inpatient or outpatient visit in either the VA or Medicare system in the given calendar year. A patient could only contribute one hospitalization per year due to a number of patients who had an excessive number of repeat admissions for the same condition. When allowing these patients to contribute all of their admissions, they heavily influenced higher hospitalization rates, especially among psychiatric admissions. Thus, in order to allow equal contributions to the annual hospitalization rate regardless of principal diagnosis, we defined the numerator as having at least one admission in the given year.

Annual hospitalization rates were stratified by both HIV serostatus and ARD history. We then stratified annual hospitalization rates by each of the 12 principal diagnosis categories. Ordinary least squares regression models were used to obtain Wald chi-square $\left(\chi^{2}\right)$ test statistics (34), which examined trends in hospitalization rates over the study period.

A multivariable Cox proportional hazards model was used to model the risk of hospitalization using both HIV serostatus and ARD as the two primary exposures of interest (34). To reduce potential biases from patients who were more likely to be hospitalized at cohort entry, only patients who did not experience a hospitalization within the first 180 days after VACS enrollment were eligible for this modeling portion of the analysis. The model controlled for prognostic factors including age at VACS enrollment, sex, race, comorbidities as defined above, and an interaction term between HIV serostatus and ARD history. All variables satisfied the proportional hazards assumption, and there was no evidence of collinearity (all condition indices $<20$ ). Statistical analyses were performed using SAS version 9.4 (SAS Institute Inc., Cary, NC, USA). Due to the large number of psychiatric hospitalizations, we also conducted a sensitivity analysis omitting these hospitalizations.

\section{RESULTS}

There were 46,428 HIV+ and 93,997 uninfected patients who fit the study inclusion criteria $(\mathrm{n}=140,425)$ and they were followed from 1997 to 2011 (1,497,536 person-years). At baseline the median age was 45 years (interquartile range [IQR] 39-51 years); most were male (98\%); $47 \%$ were black/African-American, 39\% white/Caucasian, and 7\% Hispanic (Table I). The most common comorbidities were psychiatric diagnoses (56\% among HIV+ patients vs. 53\% among uninfected patients, $\left.\chi^{2}=127.1\right)$, hypertension (50\% among HIV+ patients vs. $63 \%$ among uninfected patients, $\left.\chi^{2}=1993.8\right)$, ARDs (33\% among HIV+ patients vs. $31 \%$ among uninfected patients, $\chi^{2}=83.1$ ), and drug-related diagnoses (33\% among HIV + patients vs. $24 \%$ among uninfected patients, $\chi^{2}=1488.6$ ), and these all differed by HIV status (all $\mathrm{p}<0.0001$ ) (Table I). 
During follow-up, 72\% ( $\mathrm{n}=33,600)$ of HIV+ patients and 58\% $(\mathrm{n}=54,654)$ of uninfected patients were hospitalized (total $n=88,254$ ) a total of 545,535 times. The majority $(77 \%)$ of the hospitalizations occurred within the VA while the remaining $23 \%$ took place outside of the VA (Table II). Among those hospitalized, HIV+ patients experienced a higher median number of admissions (4 hospitalizations per patient; IQR 2-8) than uninfected patients (3 hospitalizations per patient; IQR 1-7) $(\mathrm{z}=14.0, \mathrm{p}<0.0001)$. However, both HIV+ and uninfected patients experienced a median length of stay of five days per admission (IQR 210 days). Hospitalizations with psychiatric diagnoses were the most common in this cohort. Of note, only $12 \%(n=26,045)$ of admissions among HIV+ patients were categorized as HIV/AIDS-related.

Hospitalization rates decreased over the study period for both HIV+ patients (a 32\% decrease from 304 admissions per 1000 patients in 1997 to 206 admissions per 1000 patients in 2011, $\chi^{2}=1315.9$, p-trend <0.0001) and uninfected patients (a 21\% decrease from 212 admissions per 1000 patients in 1997 to 167 admissions per 1000 patients in $2011, \chi^{2}=280.9$, p-trend $<0.0001$ ) (Figure 1a). Nearly a third of both HIV+ and uninfected individuals in this sample had an ARD at baseline or during follow-up. Hospitalization rates also decreased over the study period for those with an ARD (a 21\% decrease from 353 admissions per 1000 patients in 1997 to 279 admissions per 1000 patients in 2011, $\chi^{2}=443.1$, p-trend <0.0001) and those without an ARD (a 22\% decrease from 170 admissions per 1000 patients in 1997 to 132 admissions per 1000 patients in 2011, $\chi^{2}=289.6$, p-trend <0.0001) (Figure 1b).

While overall hospitalization rates by HIV serostatus and ARD history decreased between 1997 and 2011, the stratification of these rates by principal diagnosis category yielded contrasting results. Overall, the group at greatest risk for hospitalization was HIV+ individuals with an ARDs (Figure 2a). Hospitalizations with psychiatric, HIV/AIDS, ARD, and drug-related diagnoses significantly decreased over the study period regardless of HIV infection or ARD history (Figures $2 \mathrm{~b}-\mathrm{e}$; all $\chi^{2}>150$, all p-trend $<0.0001$ ). In addition, the hospitalization rates within these principal diagnosis categories were the highest among all the principal diagnosis categories. Conversely, hospitalizations with cardiovascular and renal insufficiency diagnoses significantly increased over the study period regardless of HIV infection or ARD history (Figures $2 \mathrm{f}-\mathrm{g}$; all $\chi^{2}>5$, all $\mathrm{p}$-trend $<0.03$ ).

Hospitalizations in all other categories, which included those with gastrointestinal (GI) and liver, endocrine, neurologic, non-AIDS cancer, respiratory, and other infection diagnoses, significantly increased among uninfected patients regardless of ARD history (Figures $2 \mathrm{~h}-\mathrm{m}$; all $\chi^{2}>16$, all p-trend $<0.0001$ ). While ARD history did not appear to be important among uninfected individuals for these hospitalizations, HIV+ individuals with an ARD experienced higher rates than HIV+ individuals without an ARD. For instance, hospitalizations with a GI and liver or an endocrine diagnosis increased significantly among HIV+ patients with an ARD (GI and liver: $\chi^{2}=6.4$, p-trend $=0.01$; endocrine: $\chi^{2}=7.4$, p-trend $<0.01$ ) but decreased among HIV+ patients without an ARD (GI and liver: $\chi^{2}=14.5$, p-trend $<0.0001$; endocrine: $\chi^{2}=27.5$, p-trend $<0.0001$ ). Furthermore, hospitalizations with neurologic or non-AIDS cancer diagnoses increased significantly among HIV+ patients with an ARD (neurologic: $\chi^{2}=76.8$, p-trend $<0.0001$; non-AIDS cancer: $\chi^{2}=186.8$, p-trend $<0.0001$ ) but there were no detected trends among HIV+ patients without an ARD 
(neurologic: $\chi^{2}=0.6$, p-trend $=0.43$; non-AIDS cancer: $\chi^{2}=0.1$, p-trend=0.77). Among HIV+ patients, respiratory hospitalization rates showed no significant change over the study period among those with an $\operatorname{ARD}\left(\chi^{2}=0.06\right.$, p-trend $\left.=0.83\right)$ but decreased among those without an $\operatorname{ARD}\left(\chi^{2}=155.9, p\right.$-trend $\left.<0.0001\right)$. Finally, hospitalizations among HIV+ patients related to other infections decreased significantly regardless of ARD history $\left(\chi^{2}>6\right.$, p-trend $\left.<0.01\right)$.

The multivariable model (Table III) assessed the risk of hospitalization between HIV+ and uninfected patients who did not experience an admission for at least 180 days after VACS enrollment. The distribution of principal diagnoses for these patients' first hospitalization was: $13 \%$ cardiovascular, $12 \%$ psychiatric, $10 \%$ GI and liver, $9 \%$ neurologic, $8 \%$ for each non-HIV/AIDS infection and respiratory, $6 \%$ for each ARD and drug-related diagnoses, $5 \%$ HIV/AIDS, $4 \%$ non-AIDS cancer, and 3\% for each endocrine and renal insufficiency. In multivariable analyses comparing to uninfected patients without an ARD, both an HIV infection (adjusted hazard ratio [aHR] 1.85, 95\% confidence interval [95\% CI] 1.81, 1.88) and an ARD (aHR 2.08, 95\% CI 2.04, 2.13) increased the risk of hospitalization.

Furthermore, those who were HIV+ with an ARD were over three times as likely to be admitted than their uninfected with no ARD counterparts (aHR 3.24, 95\% CI 3.00, 3.49).

The sensitivity analyses omitted all psychiatric diagnoses-related hospitalizations. While pvalues and proportions changed, all significant findings made when these hospitalizations were included remained (data not shown).

\section{DISCUSSION}

Since ART became available in 1996 and through 2011, overall hospitalization rates have declined 32\% for HIV+ patients (from 304 to 206 per 1000 patients) and 21\% (from 212 to 167 per 1000 patients) for uninfected patients. While overall hospitalizations among HIV+ individuals remained higher than among uninfected individuals, the excess risk dropped from 43\% (304/212 per 1000 patients in 1996) to 23\% (206/167 per 1000 patients in 2011). In contrast, the excess risk for patients with an ARD versus those without an ARD remained high over the study period starting at 108\% (353/170 per 1000 patients in 1997) and ending at $111 \%$ (279/132 per 1000 patients in 2011). Importantly, HIV infection and ARDs had additive effects.

Overall hospitalization rates decreased, mostly driven by decreases in hospitalization with psychiatric, HIV/AIDS, ARD, and drug-related diagnoses. In contrast, hospitalizations with cardiovascular and renal insufficiency diagnoses increased among all groups regardless of HIV serostatus or ARD history. Our results should not be interpreted as evidence that HIV infection is no longer "important." Rather, they suggest that people aging with HIV infection are particularly susceptible to harm from other chronic conditions like alcohol abuse, dependence, and other ARDs. This conclusion is supported by the more pronounced effects of ARDs among those with HIV infection seen for GI and liver, endocrine, neurologic, and non-AIDS cancer hospitalizations.

During the last year of follow up, HIV+ patients with an ARD had the highest rates of admission for psychiatric (72 per 1000 patients), drug-related (49 per 1000 patients), GI and 
liver (47 per 1000 patients), and alcohol-related (39 per 1000 patients) diagnoses. While this may not be surprising, it underscores the importance of addressing modifiable risk factors, such as alcohol and drug abuse, if we are to decrease morbidity and mortality associated with liver disease, a leading cause of death among those with HIV infection.

Overall, ARDs were common and added to the risk of hospitalization among those with HIV infection in unadjusted and adjusted analyses. It is particularly interesting that HIV+ individuals with ARD had the most rapid rise in non-AIDS cancer admissions and were experiencing the highest rates of admission with cancer diagnoses in the last five years of follow-up, from 2007 to 2011. Likely contributing causes include the higher prevalence of hepatitis $\mathrm{C}$ among HIV+ individuals compared with uninfected individuals (35) and their added susceptibility to liver cancer (especially in the context of ongoing heavy alcohol consumption) $(36,37)$. Additionally, heavy alcohol use is associated with heavy tobacco use (38) so ARD is also likely associated with increased rates of lung and bladder cancer.

Perhaps less well appreciated is the direct association of alcohol with other forms of cancer including colorectal cancer, breast cancer, oral cavity and pharyngeal cancer. Of note, even moderate use of alcohol may increase the risk of many of these cancers $(39,40)$. Importantly, while HIV remains a chronic infection, unhealthy alcohol use (41) is modifiable (42-45) through comprehensive treatment programs (46-48).

A potential limitation of this study was the predominantly male United States Veteran cohort, which may not be generalizable to other HIV populations. However, when comparing VACS data with data from the United States Centers for Disease Control and Prevention, VACS subjects were similar with respect to race/ethnicity and risk factors for HIV infection (49). Further, VACS data and outcomes have been compared to more than 20 HIV cohort studies in North America and Europe through collaborations with the Antiretroviral Therapy Cohort Collaboration (ART-CC) (50), the HIV-CAUSAL Collaboration (51), and the North American AIDS Cohort Collaboration on Research and Design (NA-ACCORD) (52). Routine cross-cohort analyses require that analyses be stratified by cohort prior to combining data. In all cases, relationships among variables in VACS were consistent with data from other cohorts within these collaborations and thus were included in joint analyses. Nevertheless, VACS under-represents women and hospitalization rates among women should be compared by HIV serostatus in future work.

Also of note, this analysis does not address the underlying causes of ARDs. Prior literature suggests that these are myriad among those with and without HIV infection, but among those with HIV infection, some issues (e.g., stigma, social isolation, and self-medication) may be more pronounced. Similarly, due to the greater prevalence of hepatitis $\mathrm{C}$ infection among HIV+ individuals, it is possible that some of the increased risk of hospitalization overall and for diagnosis-specific rates were due to hepatitis $\mathrm{C}$ co-infection.

\section{CONCLUSIONS}

Hospitalization rates from 1997 to 2011 have decreased among HIV+ and uninfected individuals. ARDs were common in both groups. While decreasing overall, risk of hospitalization remains higher among HIV+ individuals than uninfected individuals and is 
strongly influenced by the presence or absence of an ARD. Using effective comprehensive treatment programs to treat ARDs and their associated conditions, including psychiatric disease, could reduce inpatient utilization and overall morbidity in both HIV+ and uninfected patients.

\section{Supplementary Material}

Refer to Web version on PubMed Central for supplementary material.

\section{Acknowledgments}

This work was supported by the National Institutes of Health: AHRQ [R01-HS018372], NIAAA [U24-AA020794, U01-AA020790, U01-AA020795, U01-AA020799, U24-AA022001, U24 AA022007, U10 AA013566-completed], NHLBI [R01-HL095136; R01-HL090342], NIAID [U01-A1069918], NIMH [P30-MH062294], NIDA [R01DA035616], NCI [R01 CA173754] and the Veterans Health Administration Office of Research and Development [VA REA 08-266, VA IRR Merit Award, VISN 1 Career Development Award [V1CDA2012-20]] and Office of Academic Affiliations [Medical Informatics Fellowship]. This material is based upon work supported by the Department of Veterans Affairs, Veterans Health Administration, and Office of Research and Development. We must disclaim that the views expressed in this article are those of the authors and do not necessarily reflect the position or policy of the Department of Veterans Affairs.

\section{References}

1. Berry SA, Fleishman JA, Moore RD, Gebo KA. Trends in Reasons for Hospitalization in a Multisite United States Cohort of Persons Living With HIV, 2001-2008. J Acquir Immune Defic Syndr. 2012; 59:368-75. [PubMed: 22240460]

2. Buchacz K, Baker RK, Moorman AC, Richardson JT, Wood KC, Holmberg SD, et al. Rates of Hospitalizations and Associated Diagnoses in a Large Multisite Cohort of HIV Patients in the United States, 1994-2005. AIDS. 2008; 22:1345-56. [PubMed: 18580614]

3. Crum-Cianflone NF, Grandits G, Echols S, Ganesan A, Landrum M, Weintrob A. Trends and Causes of Hospitalizations Among HIV-Infected Persons During the Late HAART Era: What Is the Impact of CD4 Counts and HAART Use? J Acquir Immune Defic Syndr. 2010; 54:248-57. [PubMed: 20658748]

4. Bozzette S, Ake C, Tam H, Change S, Louis T. Cardiovascular and Cerebrovascular Events in Patients Treated for Human Immunodeficiency Virus Infection. N Engl J Med. 2003; 348:702-10. [PubMed: 12594314]

5. Powles T, Robinson D, Stebbing J, Shamash J, Nelson M, Gazzard B, et al. Highly active antiretroviral therapy and the incidence of non-AIDS-defining cancers in people with HIV infection. J Clin Oncol. 2009; 27(6):884-90. [PubMed: 19114688]

6. Akgun KM, Tate JP, Pisani M, Fried T, Butt AA, Gibert CL, et al. Medical ICU admission diagnoses and outcomes in human immunodeficiency virus-infected and virus-uninfected veterans in the combination antiretroviral era. Crit Care Med. 2013; 41(6):1458-67. [PubMed: 23507717]

7. Fleishman JA, Gebo KA, Reilly E, Conviser R, Mathews WC, Korthuis P, et al. Hospital and Outpatient Health Services Utilization Among HIV-Infected Adults in Care 2000-2002. Med Care. 2005; 43:III40-III52. [PubMed: 16116308]

8. Gebo KA, Diener-West M, Moore RD. Hospitalization Rates Differ by Hepatitis C Status in an Urban HIV Cohort. J Acquir Immune Defic Syndr. 2003; 34(2):165-73. [PubMed: 14526205]

9. Krentz HB, Dean S, Gill MJ. Longitudinal assessment (1995-2003) of hospitalizations of HIVinfected patients within a geographical population in Canada. HIV Med. 2006; 7:457-66. [PubMed: 16925732]

10. Krupitsky E, Horton N, Williams E, Lioznov D, Kuznetsova M, Zvartau E, et al. Alcohol use and HIV risk behaviors among HIV-infected hospitalized patients in St. Petersburg, Russia. Drug Alcohol Depend. 2005; 79(2):251-6. [PubMed: 16002034] 
11. Akgun KM, Gordon K, Pisani M, Fried T, McGinnis KA, Tate JP, et al. Risk factors for hospitalization and medical intensive care unit (MICU) admission among HIV infected Veterans. J Acquir Immune Defic Syndr. 2013; 62(1):52-9. [PubMed: 23111572]

12. Justice AC, Sullivan L, Fiellin D. HIV/AIDS, Comorbidity, and Alcohol: Can We Make A Difference? Alcohol Res Health. 2010; 33(3):258-66. [PubMed: 23584067]

13. Purohit V, Bode JC, Bode C, Brenner DA, Choudhry MA, Hamilton F, et al. Alcohol, intestinal bacterial growth, intestinal permeability to endotoxin, and medical consequences: summary of a symposium. Alcohol. 2008; 42(5):349-61. [PubMed: 18504085]

14. Lim JK, Tate JP, Fultz SL, Goulet JL, Conigliaro J, Bryant KJ, et al. Relationship between alcohol use categories and noninvasive markers of advanced hepatic fibrosis in HIV-infected, chronic hepatitis C virus-infected, and uninfected patients. Clin Infect Dis. 2014; 58(10):1449-58. [PubMed: 24569533]

15. Anderson JP, Tchetgen Tchetgen EJ, Lo Re V 3rd, Tate JP, Williams PL, Seage GR 3rd, et al. Antiretroviral therapy reduces the rate of hepatic decompensation among HIV-and hepatitis C virus-coinfected veterans. Clin Infect Dis. 2014; 58(5):719-27. [PubMed: 24285848]

16. Lo Re V III, Kallan MJ, Tate JP, Locallo AR, Lim JK, Goetz MB, et al. Hepatic Decompensation in Antiretroviral-Treated Patients Co-Infected With HIV and Hepatitis C Virus Compared With Hepatitis C Virus-Monoinfected Patients. Ann Intern Med. 2014; 160:369-79. [PubMed: 24723077]

17. Sullivan LE, Fiellin DA, O'Connor PG. The prevalence and impact of alcohol problems in major depression: a systematic review. Am J Med. 2005; 118(4):330-41. [PubMed: 15808128]

18. Sullivan LE, Goulet JL, Justice AC, Fiellin DA. Alcohol consumption and depressive symptoms over time: a longitudinal study of patients with and without HIV infection. Drug Alcohol Depend. 2011; 117(2-3):158-63. [PubMed: 21345624]

19. Alba ID, Samet JH, Saitz R. Burden of Medical Illness in Drug- and Alcohol-dependent Persons Without Primary Care. Am J Addict. 2004; 13(1):33-45. [PubMed: 14766436]

20. Kirchner JE, Zubritsky C, Cody M, Coakley E, Chen H, Ware JH, et al. Alcohol consumption among older adults in primary care. J Gen Intern Med. 2007; 22(1):92-7. [PubMed: 17351846]

21. Saitz R, Horton NJ, Sullivan LM, Moskowitz MA, Samet JH. Addressing Alcohol Problems in Primary Care: A Cluster Randomized, Controlled Trial of a Systems Intervention. Ann Intern Med. 2003; 138:372-82. [PubMed: 12614089]

22. McDonald SA, Hutchinson SJ, Bird SM, Graham L, Robertson C, Mills PR, et al. Association of self-reported alcohol use and hospitalization for an alcohol-related cause in Scotland: a recordlinkage study of 23,183 individuals. Addiction. 2009; 104(4):593-602. [PubMed: 19335657]

23. Azar MM, Springer SA, Meyer JP, Altice FL. A systematic review of the impact of alcohol use disorders on HIV treatment outcomes, adherence to antiretroviral therapy and health care utilization. Drug Alcohol Depend. 2010; 112(3):178-93. [PubMed: 20705402]

24. Gordon A, McGinnis KA, Conigliaro J, Rodriguez-Barradas M, Rabeneck L, Justice AC. Associations between Alcohol Use and Homelessness with Healthcare Utilization among Human Immunodeficiency Virus-Infected Veterans. Med Care. 2006; 44(8):S37-S43. [PubMed: 16849967]

25. Kraemer K, McGinnis KA, Skanderson M, Cook R, Gordon A, Conigliaro J, et al. Alcohol Problems and Health Care Services Use in Human Immunodeficiency Virus (HIV)-lnfected and HIV-Uninfected Veterans. Med Care. 2006; 44(8):S44-S51. [PubMed: 16849968]

26. Palepu A, Horton NJ, Tibbetts N, Meli S, Samet JH. Substance Abuse Treatment and Hospitalization among a Cohort of HIV-Infected Individuals with Alcohol Problems. Alcohol Clin Exp Res. 2005; 29(3):389-94. [PubMed: 15770114]

27. Cunningham W, Sohler N, Tobias C, Drainoni M, Bradford J, Davis C, et al. Health Services Utilization for People with HIV Infection: Comparison of a Population Targeted for Outreach with the U.S. Population in Care. Med Care. 2006; 44(11):1038-47. [PubMed: 17063136]

28. Josephs JS, Fleishman JA, Korthuis PT, Moore RD, Gebo KA, Network HIVR. Emergency department utilization among HIV-infected patients in a multisite multistate study. HIV Med. 2010; 11(1):74-84. [PubMed: 19682102] 
29. Kim TW, Kertesz SG, Horton NJ, Tibbetts N, Samet JH. Episodic homelessness and health care utilization in a prospective cohort of HIV-infected persons with alcohol problems. BMC Health Serv Res. 2006; 6:19. [PubMed: 16504167]

30. Masson CL, Sorensen JL, Phibbs CS, Okin RL. Predictors of medical service utilization among individuals with co-occurring HIV infection and substance abuse disorders. AIDS Care. 2004; 16(6):744-55. [PubMed: 15370062]

31. Fultz SL, Skanderson M, Mole L, Gandhi N, Bryant K, Crystal S, et al. Development and Verification of a "Virtual" Cohort Using the National VA Health Information System. Med Care. 2006; 44:S25-S30. [PubMed: 16849965]

32. Justice AC, Dombrowski E, Conigliaro J, Fultz SL, Gibson D, Madenwald T, et al. Veterans Aging Cohort Study (VACS): Overview and Description. Med Care. 2006; 44(8):S13-S24. [PubMed: 16849964]

33. Justice AC, Lasky E, McGinnis KA, Skanderson M, Conigliaro J, Fultz SL, et al. Medical Disease and Alcohol Use among Veterans with Human Immunodeficiency Infection: A Comparison of Disease Measurement Strategies. Med Care. 2006; 44(8):S52-S60. [PubMed: 16849969]

34. Rosner, B. Fundamentals of Biostatistics. 7. Boston, MA: Brooks/Cole; 2010.

35. Rancinan C, Neau D, Savès M, Lawson-Ayayi S, Bonnet F, Mercié $P$, et al. Is hepatitis C virus coinfection associated with survival in HIV-infected patients treated by combination antiretroviral therapy? AIDS. 2002; 16:1357-62. [PubMed: 12131212]

36. Benhamou Y, Bochet M, Martino VD, Charlotte F, Azria F, Coutellier A, et al. Liver Fibrosis Progression in Human Immunodeficiency Virus and Hepatitis C Virus Coinfected Patients. Hepatology. 1999; 30(4):1054-8. [PubMed: 10498659]

37. Park LS, Tate JP, Justice AC, Lo Re V 3rd, Lim JK, Brau N, et al. FIB-4 index is associated with hepatocellular carcinoma risk in HIV-infected patients. Cancer Epidemiol Biomarkers Prev. 2011; 20(12):2512-7. [PubMed: 22028407]

38. John U, Meyer C, Rumpf H-J, Hapke U. Probabilities of alcohol high-risk drinking, abuse or dependence estimated on grounds of tobacco smoking and nicotine dependence. Addiction. 2003; 98:805-14. [PubMed: 12780369]

39. Bagnardi V, Blangiardo M, Vecchia CL, Corrao G. Alcohol Consumption and the Risk of Cancer. Alcohol Res Health. 2001; 25(4):263-70. [PubMed: 11910703]

40. Bagnardi V, Rota M, Botteri E, Tramacere I, Islami F, Fedirko V, et al. Light alcohol drinking and cancer: a meta-analysis. Ann Oncol. 2013; 24(2):301-8. [PubMed: 22910838]

41. Saitz R. Unhealthy Alcohol Use. N Engl J Med. 2005; 352:596-607. [PubMed: 15703424]

42. Wang L, Porter B, Maynard C, Evans G, Bryson C, Sun H, et al. Predicting Risk of Hospitalization or Death Among Patients Receiving Primary Care in the Veterans Health Administration. Med Care. 2013; 51(4):368-73. [PubMed: 23269113]

43. Clark BJ, Moss M. Secondary prevention in the intensive care unit: does intensive care unit admission represent a "teachable moment?". Crit Care Med. 2011; 39(6):1500-6. [PubMed: 21494113]

44. Samet JH, Walley A. Interventions Targeting HIV-Infected Risky Drinkers. Alcohol Res Health. 2010; 33(3):267-79. [PubMed: 23584068]

45. Williams EC, Palfai T, Cheng DM, Samet JH, Bradley KA, Koepsell TD, et al. Physical health and drinking among medical inpatients with unhealthy alcohol use: a prospective study. Alcohol Clin Exp Res. 2010; 34(7):1257-65. [PubMed: 20477765]

46. Whitlock EP, Polen MR, Green CA, Orleans T, Klein J. Behavioral Counseling Interventions in Primary Care To Reduce Risky/Harmful Alcohol Use by Adults: A Summary of the Evidence for the U.S. Preventive Services Task Force. Ann Intern Med. 2004; 140:557-68. [PubMed: 15068985]

47. Wilk AI, Jenson NM, Havighurst TC. Meta-analysis of Randomized Control Trials Addressing Brief Interventions in Heavy Alcohol Drinkers. J Gen Intern Med. 1997; 12:274-83. [PubMed: 9159696]

48. Jonas DE, Amick HR, Feltner C, Bobashev G, Thomas K, Wines R, et al. Pharmacotherapy for adults with alcohol use disorders in outpatient settings: a systematic review and meta-analysis. JAMA. 2014; 311(18):1889-900. [PubMed: 24825644] 
49. Berry SA, Fleishman JA, Moore RD, Gebo KA. Trends in Reasons for Hospitalization in a Multisite United States Cohort of Persons Living with HIV, 2001-2008. J Acquir Immune Defic Syndr. 2012; 59:368-75. [PubMed: 22240460]

50. May MT, Ingle SM, Costagliola D, Justice AC, de Wolf F, Cavassini M, et al. Cohort profile: Antiretroviral Therapy Cohort Collaboration (ART-CC). Int J Epidemiol. 2013; 43(3):691-702. [PubMed: 23599235]

51. Ray M, Logan R, Sterne JA, Hernandez-Diaz S, Robins JM, et al. HIV-Causal Collaboration. The effect of combined antiretroviral therapy on the overall mortality of HIV-infected individuals. AIDS. 2010; 24(1):123-37. [PubMed: 19770621]

52. Gange SJ, Kitahata MM, Saag MS, Bangsberg DR, Bosch RJ, Brooks JT, et al. Cohort profile: the North American AIDS Cohort Collaboration on Research and Design (NA-ACCORD). Int J Epidemiol. 2007; 36(2):294-301. [PubMed: 17213214] 


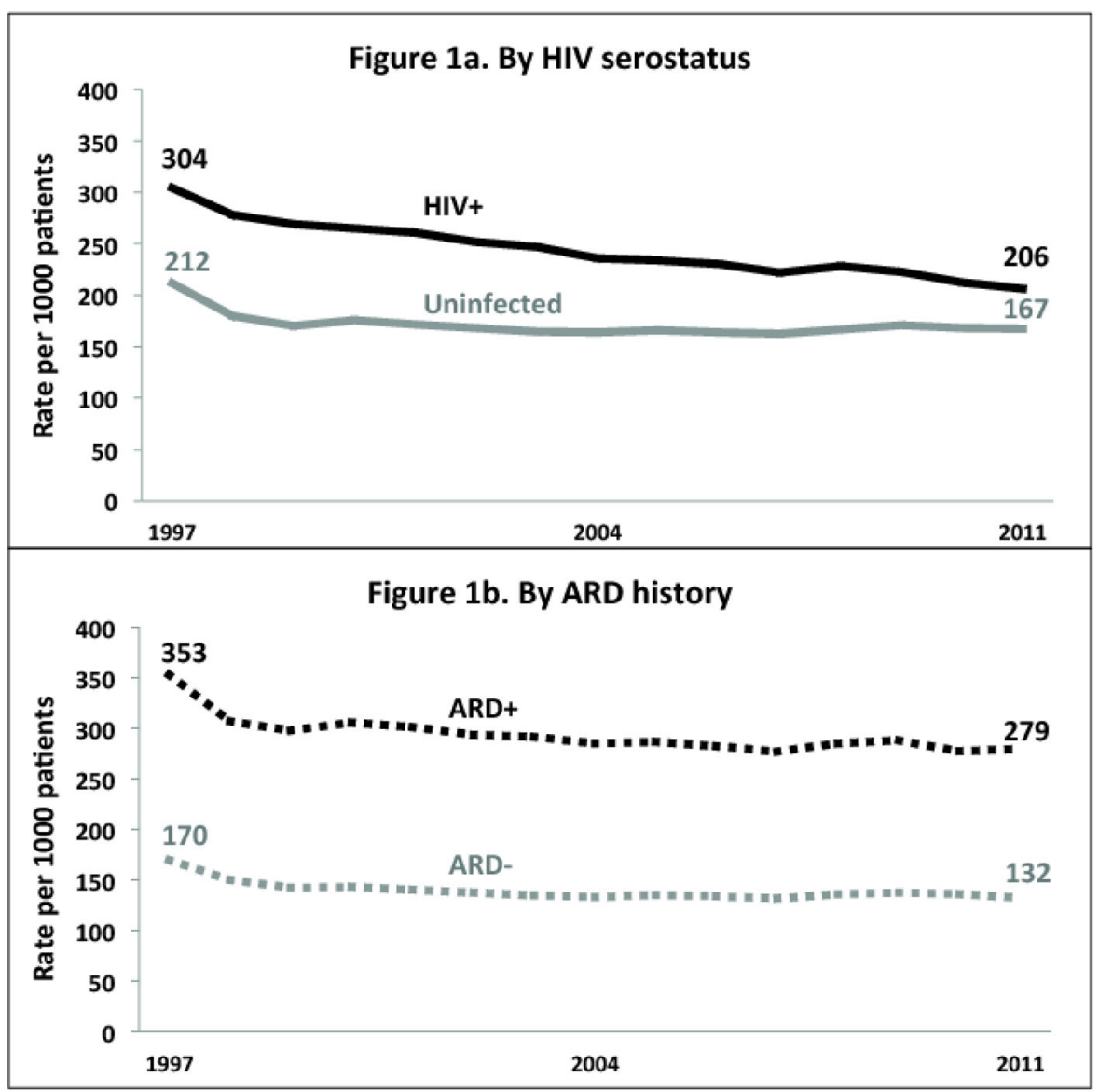

Figure 1.

Hospitalization rates per 1000 at-risk patients enrolled in VACS from 1997 to 2011 VACS - Veterans Aging Cohort Study; HIV - human immunodeficiency virus; ARD alcohol-related diagnosis 


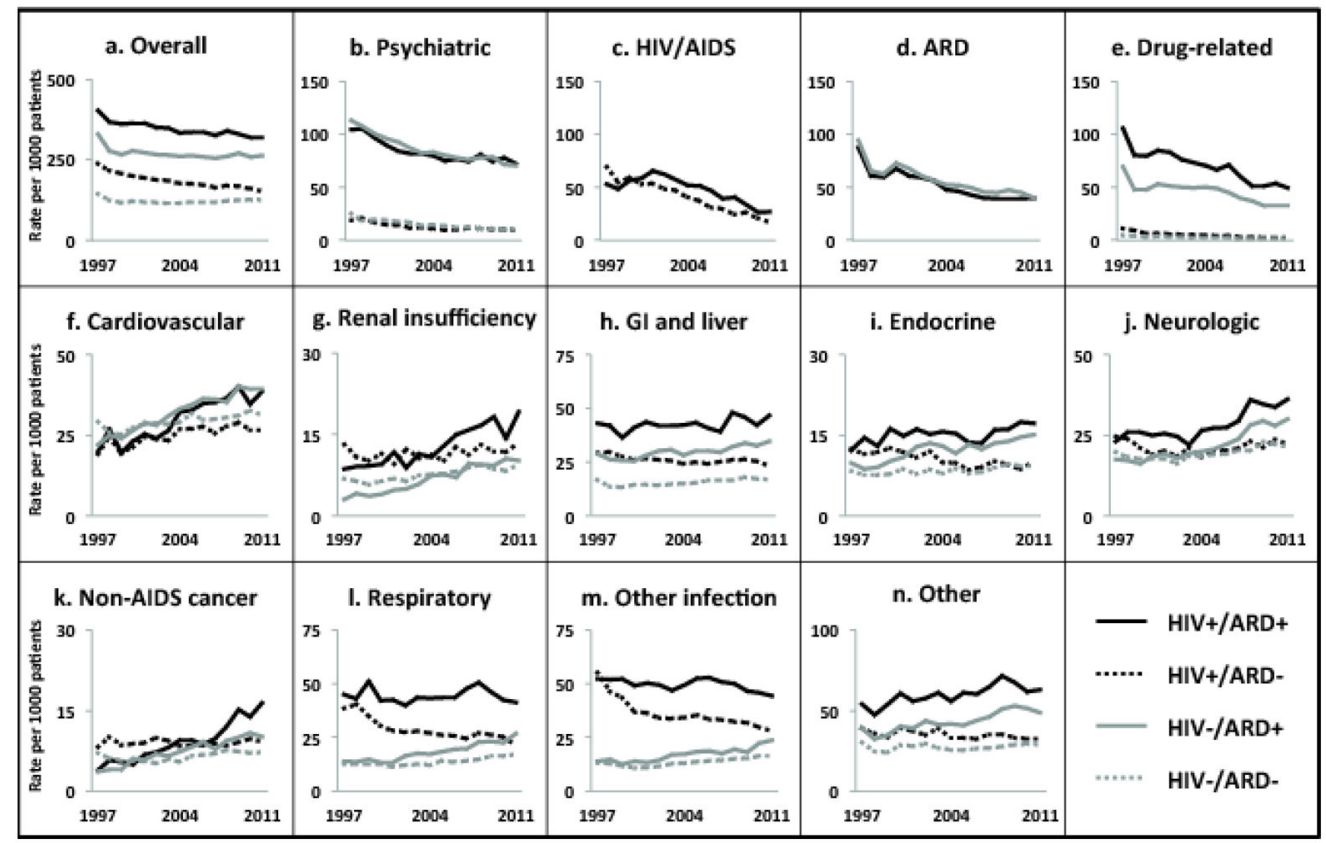

Figure 2.

Diagnosis-specific hospitalization rates per 1000 at-risk patients enrolled in VACS from 1997 to 2011 by HIV serostatus and ARD history

VACS - Veterans Aging Cohort Study; HIV - human immunodeficiency virus; ARD alcohol-related diagnosis; GI - gastrointestinal; AIDS - acquired immune deficiency syndrome 


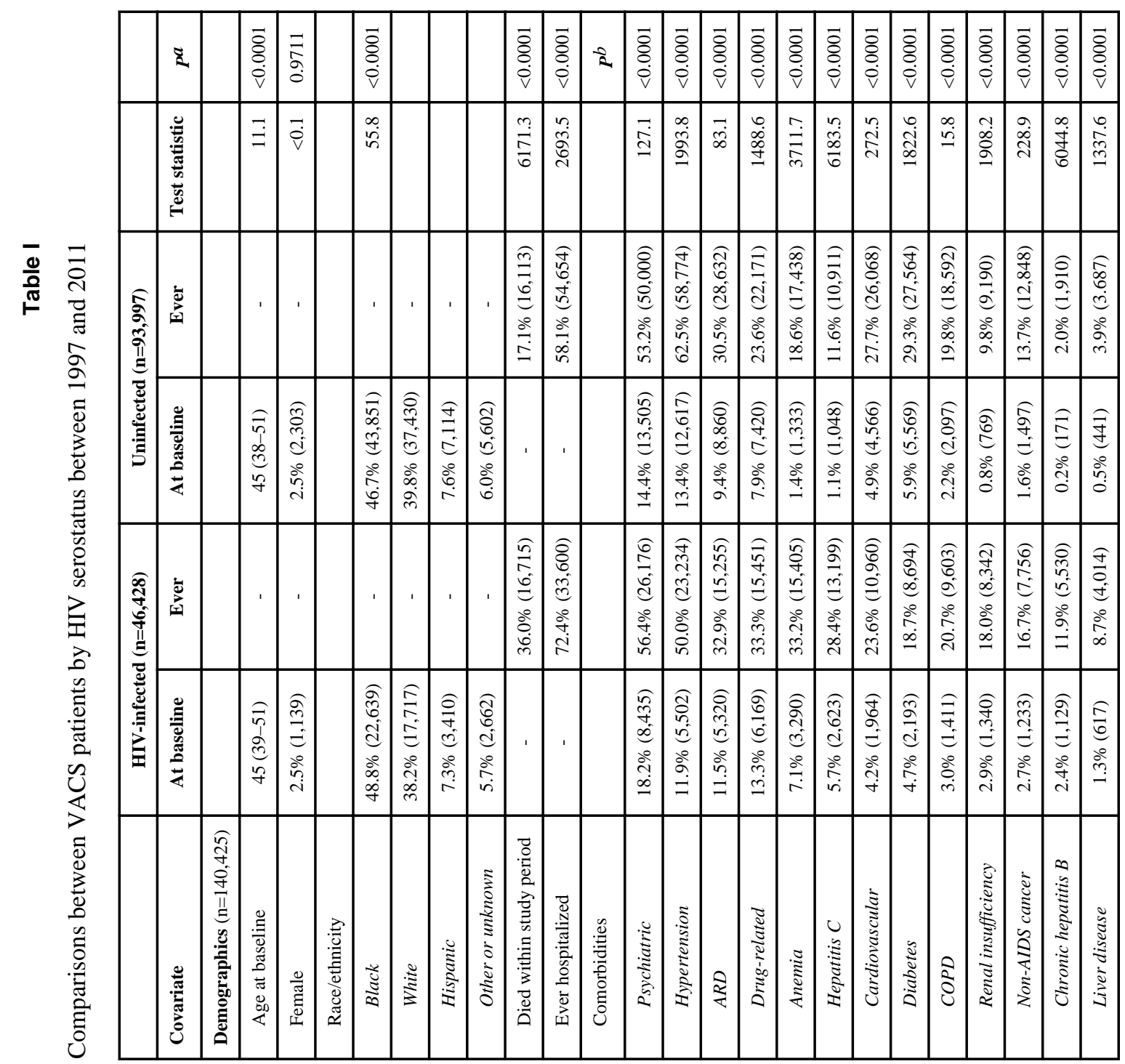

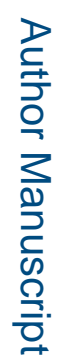

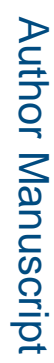


Rentsch et al.

Page 15

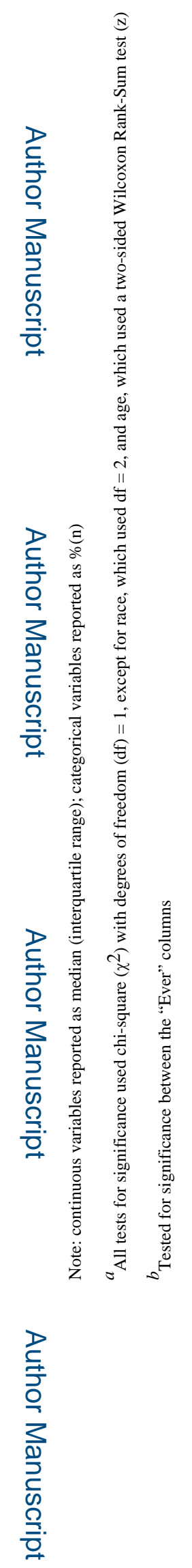

AIDS Behav. Author manuscript; available in PMC 2017 March 01. 


\section{Table II}

Hospitalization characteristics by HIV serostatus between 1997 and 2011

\begin{tabular}{|c|c|c|c|c|}
\hline Covariate & HIV-infected $(n=214,815)$ & Uninfected $(n=330,720)$ & Test statistic & $P^{a}$ \\
\hline \multicolumn{5}{|l|}{ Hospitalizations } \\
\hline \multicolumn{5}{|l|}{ System } \\
\hline Internal (VA) & $77.1 \%(165,621)$ & $76.7 \%(253,636)$ & 12.7 & 0.0004 \\
\hline External (Medicare) & $22.9 \%(49,227)$ & $23.3 \%(77,174)$ & & \\
\hline Median length of stay per hospitalization, days & $5(2-10)$ & $5(2-10)$ & 13.8 & $<0.0001$ \\
\hline \multicolumn{5}{|l|}{ Primary admission diagnosis category } \\
\hline Psychiatric & $13.1 \%(28,233)$ & $19.9 \%(65,884)$ & 4191.4 & $<0.0001$ \\
\hline HIV/AIDS & $12.1 \%(26,045)$ & - & & - \\
\hline Cardiovascular & $7.8 \%(16,774)$ & $13.5 \%(44,735)$ & 4256.2 & $<0.0001$ \\
\hline GI and liver & $8.4 \%(18,031)$ & $8.3 \%(27,458)$ & 1.4 & 0.2342 \\
\hline$A R D$ & $6.0 \%(12,844)$ & $9.3 \%(30,593)$ & 1901.7 & $<0.0001$ \\
\hline Drug-related & $8.7 \%(18,655)$ & $7.3 \%(23,975)$ & 372.2 & $<0.0001$ \\
\hline Other infection & $10.2 \%(21,964)$ & $5.8 \%(19,236)$ & 3624.6 & $<0.0001$ \\
\hline Respiratory & $8.5 \%(18,195)$ & $6.4 \%(21,228)$ & 817.4 & $<0.0001$ \\
\hline Neurologic & $5.8 \%(12,344)$ & $7.6 \%(24,985)$ & 668.1 & $<0.0001$ \\
\hline Endocrine & $2.9 \%(6,308)$ & $3.7 \%(12,366)$ & 253.8 & $<0.0001$ \\
\hline Renal insufficiency & $3.1 \%(6,642)$ & $3.0 \%(9,924)$ & 3.7 & 0.0550 \\
\hline Non-AIDS cancer & $2.7 \%(5,724)$ & $3.1 \%(10,252)$ & 86.8 & $<0.0001$ \\
\hline Other & $10.7 \%(23,056)$ & $12.1 \%(40,084)$ & 244.9 & $<0.0001$ \\
\hline
\end{tabular}

Abbreviations: VACS - Veterans Aging Cohort Study; HIV - human immunodeficiency virus; VA - Veterans Affairs Healthcare System; AIDS acquired immune deficiency syndrome; GI - gastrointestinal; ARD - alcohol-related diagnosis

Note: all percentages based on total number of hospitalizations within each group and reported as \%(n); continuous variables reported as median (interquartile range)

${ }^{a}$ All tests for significance used chi-square $\left(\chi^{2}\right)$ with degrees of freedom $=1$, except for years to hospitalization, number of hospitalizations, and length of stay, which used two-sided Wilcoxon Rank-Sum tests (z) 


\section{Table III}

Multivariate results for risk to first hospitalization

\begin{tabular}{|c|c|}
\hline Covariate & Adjusted HR (95\% CI) \\
\hline \multicolumn{2}{|l|}{ HIV and ARD categories } \\
\hline$H I V+/ A R D+$ & $3.24(3.00,3.49)$ \\
\hline$H I V+/ A R D-$ & $1.85(1.81,1.88)$ \\
\hline$H I V-/ A R D+$ & $2.08(2.04,2.13)$ \\
\hline$H I V-/ A R D-$ & ref \\
\hline Baseline year & $0.95(0.95,0.96)$ \\
\hline Age at baseline & $1.03(1.03,1.03)$ \\
\hline Male sex & $0.90(0.86,0.95)$ \\
\hline \multicolumn{2}{|l|}{ Race and ethnicity } \\
\hline African-American/Black & $1.05(1.03,1.07)$ \\
\hline Hispanic & $0.89(0.86,0.91)$ \\
\hline Other/unknown & $0.55(0.53,0.58)$ \\
\hline Caucasian/White & ref \\
\hline \multicolumn{2}{|l|}{ Baseline comorbidity } \\
\hline Psychiatric & $1.27(1.24,1.30)$ \\
\hline Hypertension & $1.07(1.05,1.10)$ \\
\hline Drug-related & $1.21(1.18,1.25)$ \\
\hline Anemia & $1.76(1.66,1.86)$ \\
\hline Hepatitis $C$ & $1.18(1.11,1.25)$ \\
\hline Cardiovascular & $1.74(1.67,1.81)$ \\
\hline Diabetes & $1.34(1.29,1.38)$ \\
\hline$C O P D$ & $1.53(1.45,1.61)$ \\
\hline Non-AIDS cancer & $1.38(1.30,1.46)$ \\
\hline Chronic hepatitis B & $1.47(1.33,1.64)$ \\
\hline Liver disease & $2.04(1.81,2.30)$ \\
\hline
\end{tabular}

Abbreviations: HR - hazard ratio; CI - confidence interval; HIV - human immunodeficiency virus; ARD - alcohol-related diagnosis; ref - referent group; COPD - chronic obstructive pulmonary disorder; AIDS - acquired immune deficiency syndrome 